\title{
MALC 1987
}

\author{
By Marva L. DeLoach
}

Head, Cataloging \& Records Maintenance Illinois State University and Lynetta Lewis Alexander

Cataloger

Illinois State University

\section{The Midwest Academic Library Conference at Illinois}

\section{State University.}

he Midwest Academic Library Conference (MALC) does not have a creed, officers, committees, or dues. MALC's organizational structure is so loose, in fact, that we are not even certain about its official name. For example, previous accounts in College \& Research Libraries by H. Vail Deale referred to the gathering as the "Midwest Academic Librarians Conference." This informality continues the tradition that began in May 1956 at Michigan State University in East Lansing, Michigan.

One of its few traditions is that MALC has been jointly sponsored by several neighboring academic institutions. For the 1987 conference, Illinois State University (Normal) and Illinois Wesleyan University (Bloomington) cosponsored "Toward Holistic Library Services: Putting the Pieces Together" (May 27-29, 1987), a follow-up on the 1986 conference held at Iowa State University (Ames).

Approximately 175 people, including a visitor from California, gathered to hear such speakers as Congressman Major R. Owens (D-NY), JoAn Segal, (ACRL's executive director), Evan Farber (Earlham College), Michael Gorman (University of Illinois at Urbana-Champaign), and William Nugent (Library of Congress), present and exchange their ideas with participants. Segal, Evans

\footnotetext{
${ }^{\mathrm{I}}$ See H. Vail Deale, "A Decade with MALC," $C$ \& RL 25 (November 1964):475-82; and "MALC's Second Decade: Commitment to Communication," C\&RL 36 (March 1975):143-51.
}

and Gorman set the pace at the opening session with "Challenges for Libraries," "BI: Past, Present and Future Challenges," and "Technology: The Problem or the Solution." The conference concluded with the presentation, "Putting the Pieces Together: An Administrator's Perspective," by Thomas Shaughnessy, University of Missouri. All of them were provocative!

A pig roast and banquet at the ISU Foundation's Ewing Manor, the estate of the late Hazel Buck Ewing patterned after an English castle with a Japanese garden, were held to provide librarians with an informal atmosphere for hammering out ideas about holistic library services.

Participants were encouraged to tour the Illinois State University Library. Unfortunately, Illinois Wesleyan's beautiful facility was temporarily closed for asbestos removal, a situation that others may perhaps empathize with.

Thomas Shaughnessy summarized some of the problems discussed at the conference in his wrapup talk. Shaughnessy pointed out that good library habits must be formed in one's student years and that a campus-wide campaign must be mounted to alert students and administrators to the services and information available at their libraries. Currently, he said, university faculty and administrators are trying to resolve a myriad of diverse problems such as "bright flight," student retention, minority recruitment, and training foreign teaching assistants to speak English. Quite often campus planning does not include libraries in these finan- 
cially draining endeavors.

Pressure encourages competition, not collaboration, and Shaughnessy strongly believes that the library must promote collaboration. He encouraged library workers to become involved in these campus-wide problems and suggested that a database search of a topic could illustrate interest to university administrators, as would cooperating in a program to help students learn to write more effectively.

In order for the library staff to cope with all of these demands, Shaughnessy feels that staff development should begin on day one of employment. Since its staff is a key to a library's success, Shaughnessy develops a theme each year, such as grant writing, for staff development. Interestingly, Shaughnessy believes that attending conferences such as MALC are costly in both lost work time and hard dollars and benefit individual staff members only-not the institutions that bear most of the costs.

JoAn Segal stated that current library practices contribute to personnel specialization rather than generalization. In order to create a holistic library, administrators must urge library staff to interact beyond their own departments. She closely examined the theme of "holistic library services" and presented an intriguing picture of the library as a system interacting with a web of other systems.

Michael Gorman agreed that libraries are undervalued by faculty and society at large, and that the library's passivity to the outside world contributes to this attitude. Gorman explained that in the last decade there has been little additional money for services that are in high demand. Library managers are now challenged to cope with rising expectations among staff members who are seeking more job responsibility and fulfillment.

Gorman said that although automation has made personnel redeployment possible, he admitted that reorganization is hard to implement. He recommended that administrators redefine staff and library roles, then decide the most cost effective way to enforce reorganization. Professional duties will be encouraged and specific tasks will drift down to the lowest level at which the task can be performed. Eventually these actions will result in more resources for the user, Gorman said.

Evan Farber described the effect that automation and other new technologies will have on the intellectual framework of the campus over the next 15 years. He reassured the audience that students' need for information and assistance in evaluating data will persist.

William Nugent related the Library of Congress's progress with optical disk technology. One optical disk can store several shelves of magazines and can also provide more public access to such items as rare photographs. In addition, mechanized indexing will provide better access to collections and preserve images longer than the printed page. When concern was expressed that optical

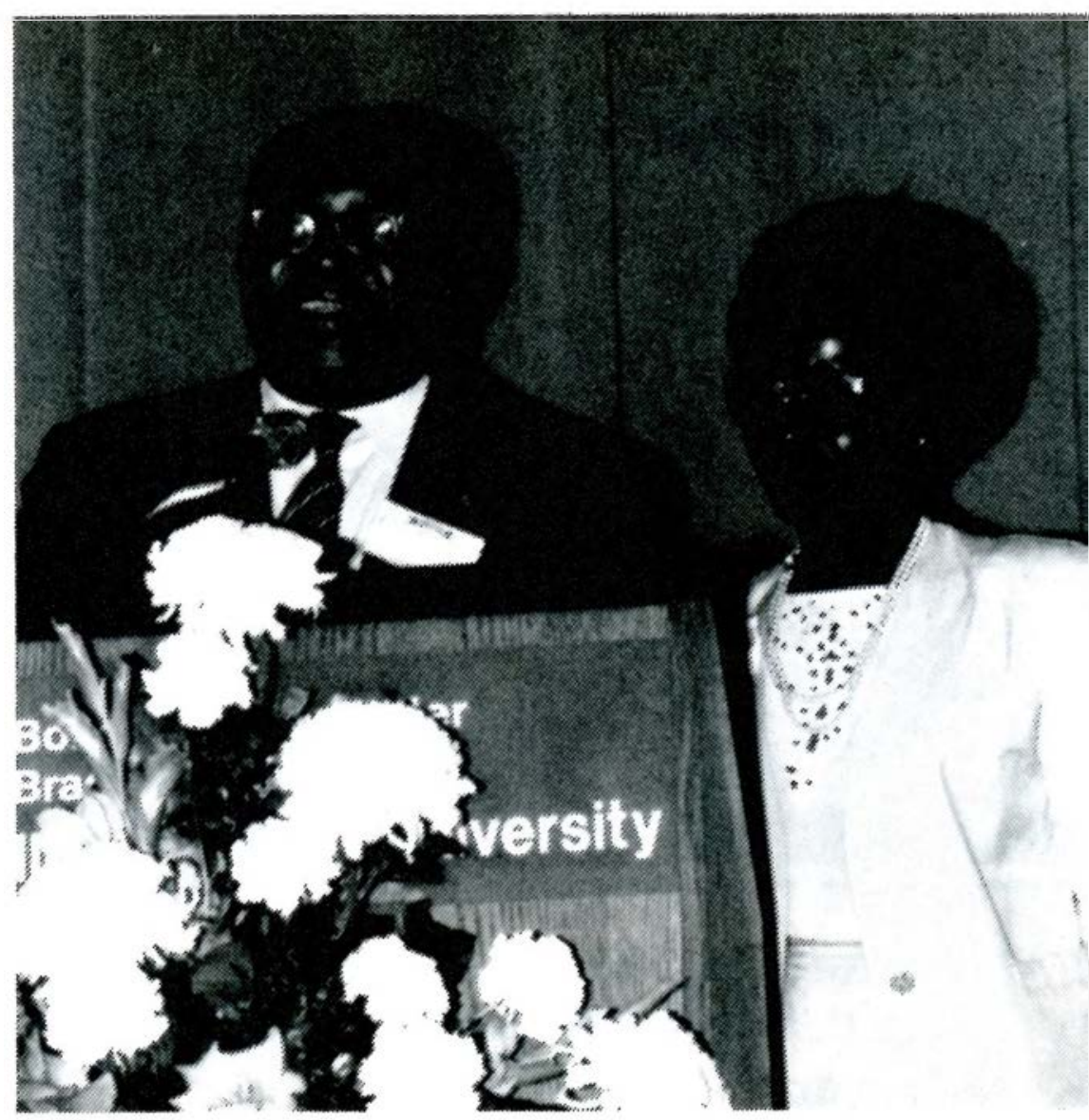

Major R. Owens answers questions after the $M A L C$ banquet as author DeLoach looks on.

disks may only have a lifetime of $10-20$ years, $\mathrm{Nu}$ gent reported that a final verdict had not been reached on disk longevity.

Other conference speakers were Doug Bedient (Southern Illinois University) on video technology; Betsy Baker (Northwestern University) on training end-users in database searching; Linda Piele, Harold Tuckett, and Donna Nicholson (University of Wisconsin-Parkside) on microcomputers; Dana Smith (Purdue University) on computer-assisted bibliographic instruction; Gerald Cole (Illinois State University) on bibliographic instruction in history; Florence Lewis (Sangamon State University) on the instructional services librarian; Judy Rycombel (DePaul University) and Mary Marshall (OCLC) on document delivery; and Tom Dorst (Depaul University), Beth Sandore and Bernie Sloan (University of Illinois, Urbana-Champaign) on resource sharing using the LCS system.

Congressman Major R. Owens, the only librarian in Congress, gave a stimulating speech at the Thursday night banquet (in the same time slot as his son, who plays Elvin on "The Cosby Show"!). He urged librarians to continually remind elected officials of our contributions to society and the need for improved library funding. He pointed out a number of bills, many that he had sponsored, which are of special interest to academic librarians.

The 1988 MALC will be at the University of Wisconsin-Milwaukee, which also sponsored a 1974 MALC meeting. Kansas State University, Manhattan, will host the 1989 program.

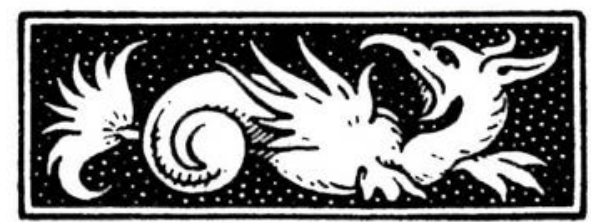




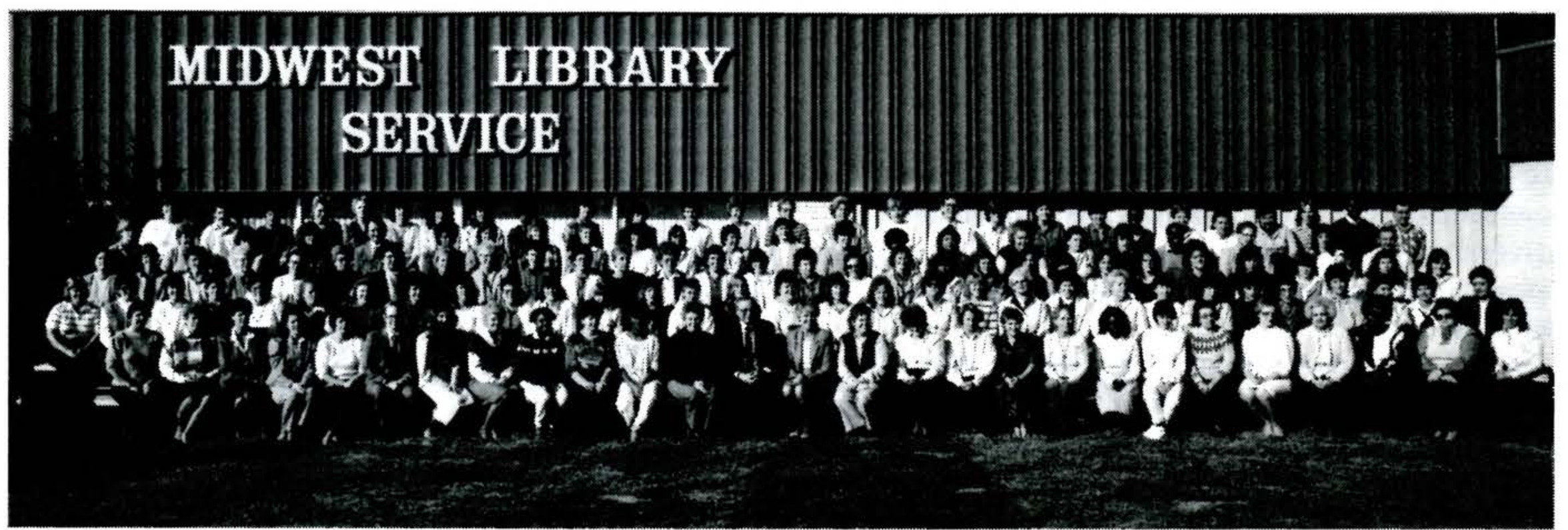

\section{When You Call MLS, The Whole Team Answers!}

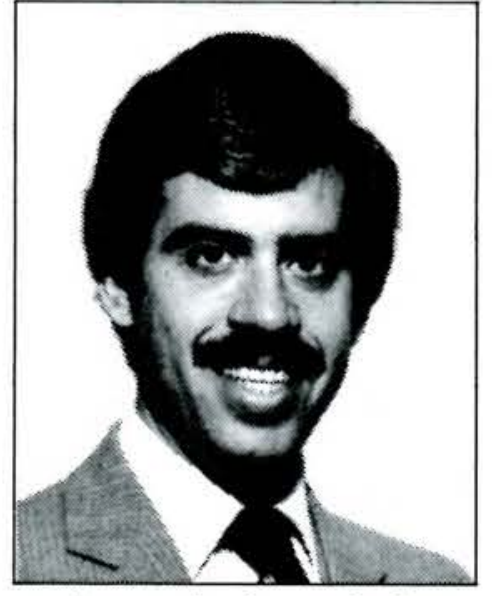

Jay Askuvich General Sales Manager

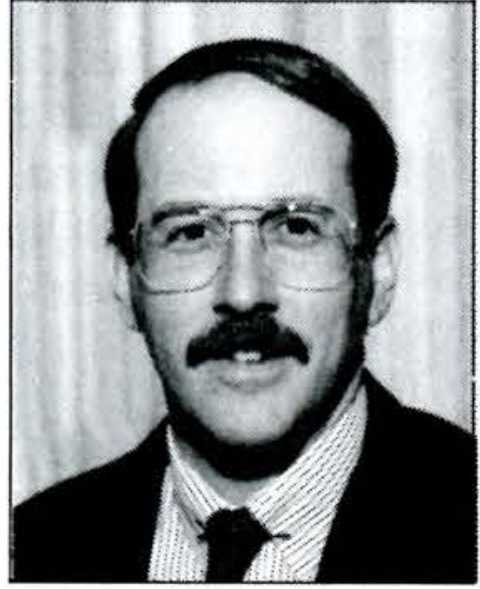

Scott Schmidt Midwest

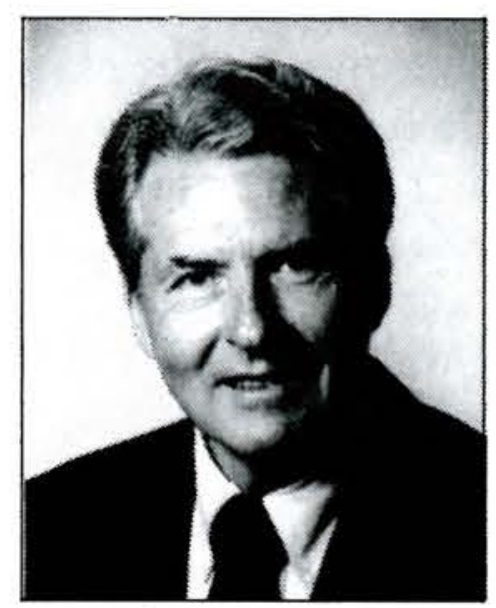

Carl Dorr

Southeast

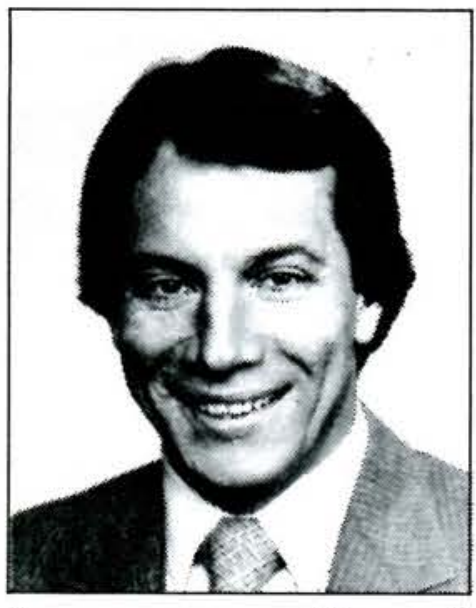

Lawrence Nagel West

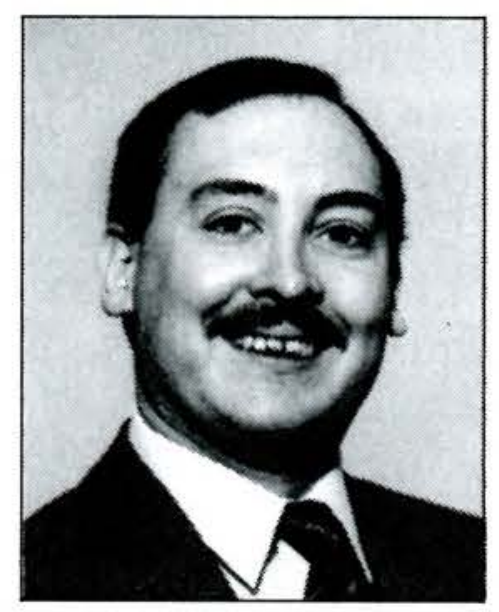

Forrest Link Northeast

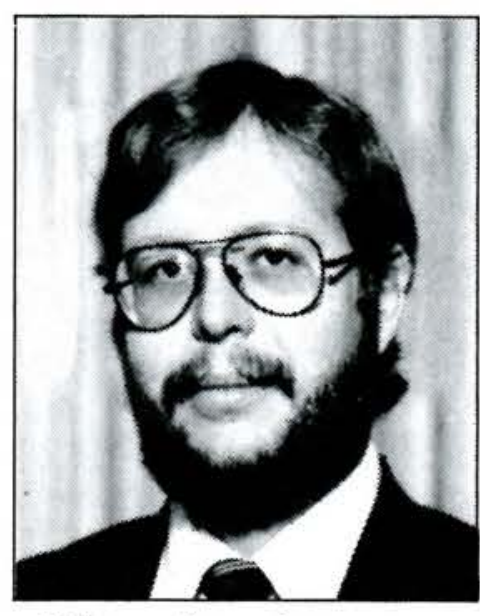

Kim Anderson Mountain Plains

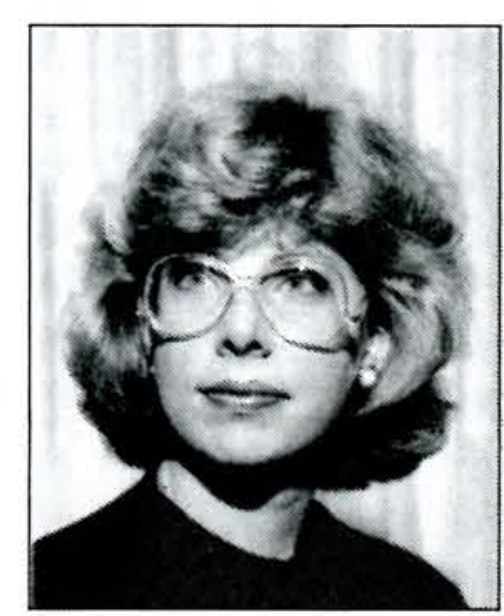

Lorraine Best Canada

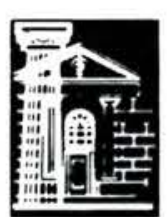

Midwest Library Service

11443 St. Charles Rock Road Bridgeton, MO 63044, USA

Call toll-free 1-800-325-8833

Missouri librarians call toll-free 1-800-392-5024

Canadian librarians call toll-free 1-800-527-1659 


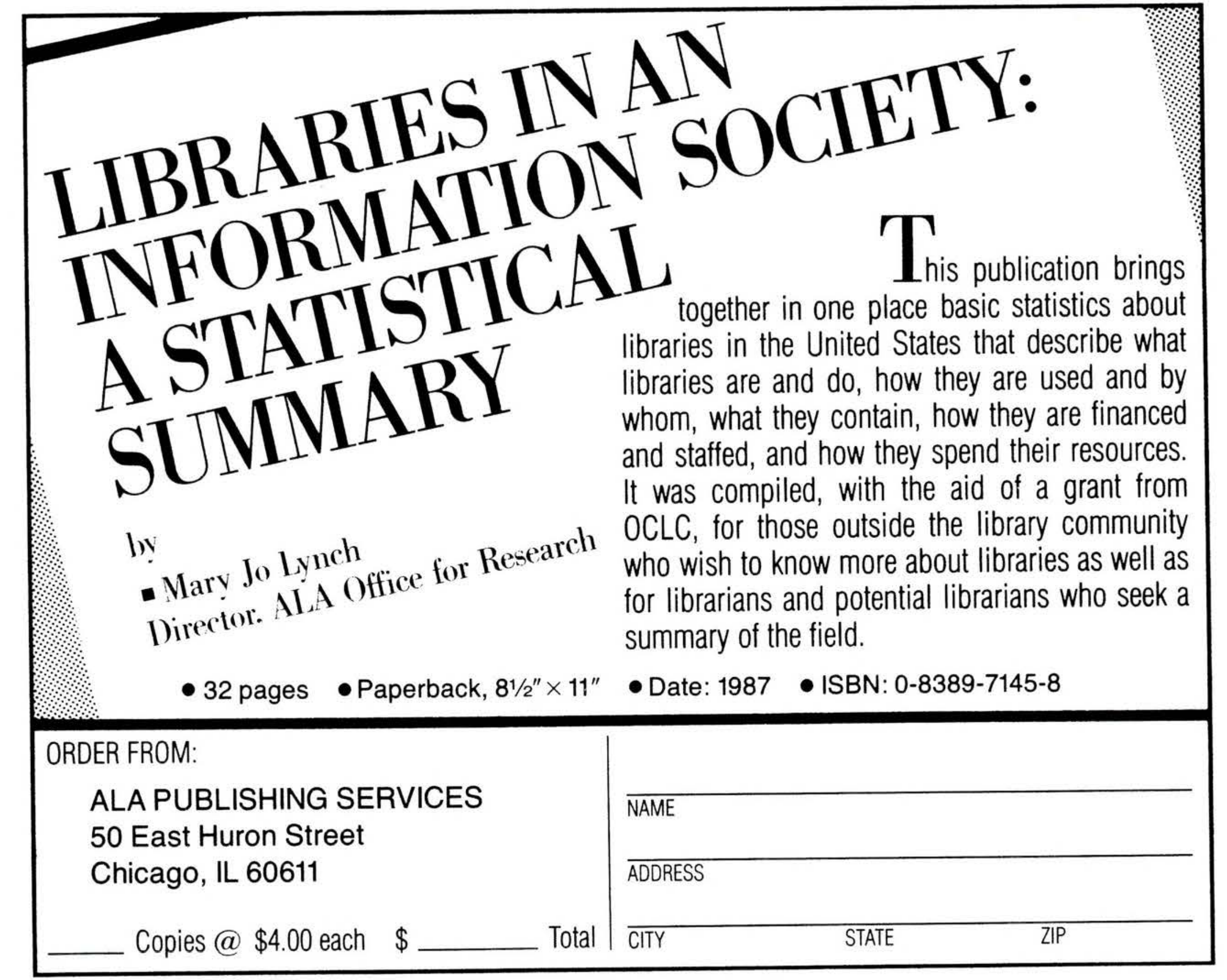

\section{ACRL'S FAST JOB LISTING}

Looking for a job? Our Fast Job Listing will send you job postings received at ACRL headquarters fourweeks before they appear in CむRL News. The Fast Job Listing Service also contains advertisements which, because of narrow application deadlines, will not appear in $C \triangleleft R L N e w s$.

The ACRL office prepares a Fast Job Listing circular at the beginning of each month and mails it to subscribers first class. The circular contains all job announcements received during the previous four weeks.

The cost of a six-month subscription is $\$ 10$ for ACRL members and $\$ 15$ for nonmembers. You may enter your subscription below.

Please enter my subscription to the ACRL Fast Job Listing Service.

I am a member of ACRL and am enclosing $\$ 10$.

I am not a member of ACRL and am enclosing $\$ 15$.

NAME:

ADDRESS:

Please make checks payable to ACRL/ALA and send to Fast Job Listing Service, ACRL/ALA, 50 E. Huron ST., Chicago, IL 60611. 